\title{
Alcohol Use and Rural Youth
}

SEDRD \& OMAFRA 2018 Rural Symposium 


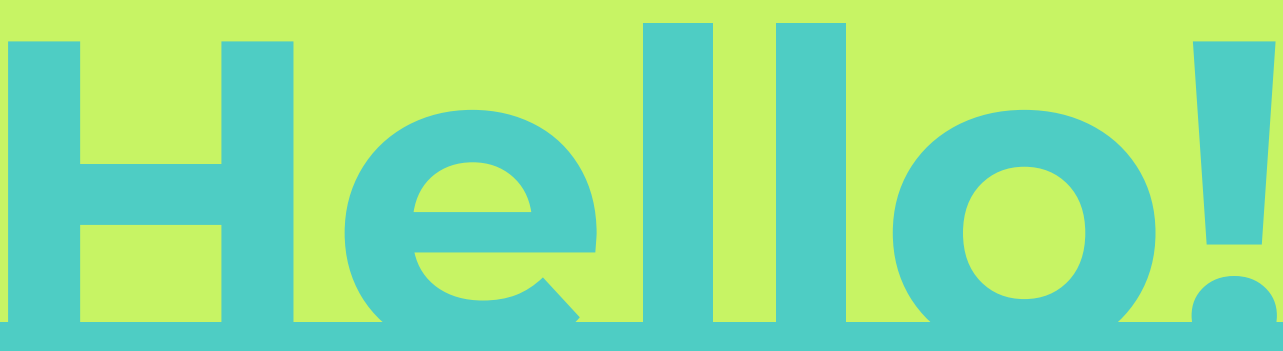

I am Jean Thompson

Part-Time Graduate Student in CDE Full-Time Wellness Educator at UofC Trying to delve into my thesis topic 


\section{How I Got Here}

My Interest in Alcohol Use and Rural Youth 

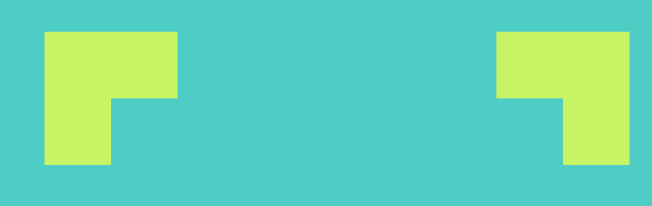

(20)
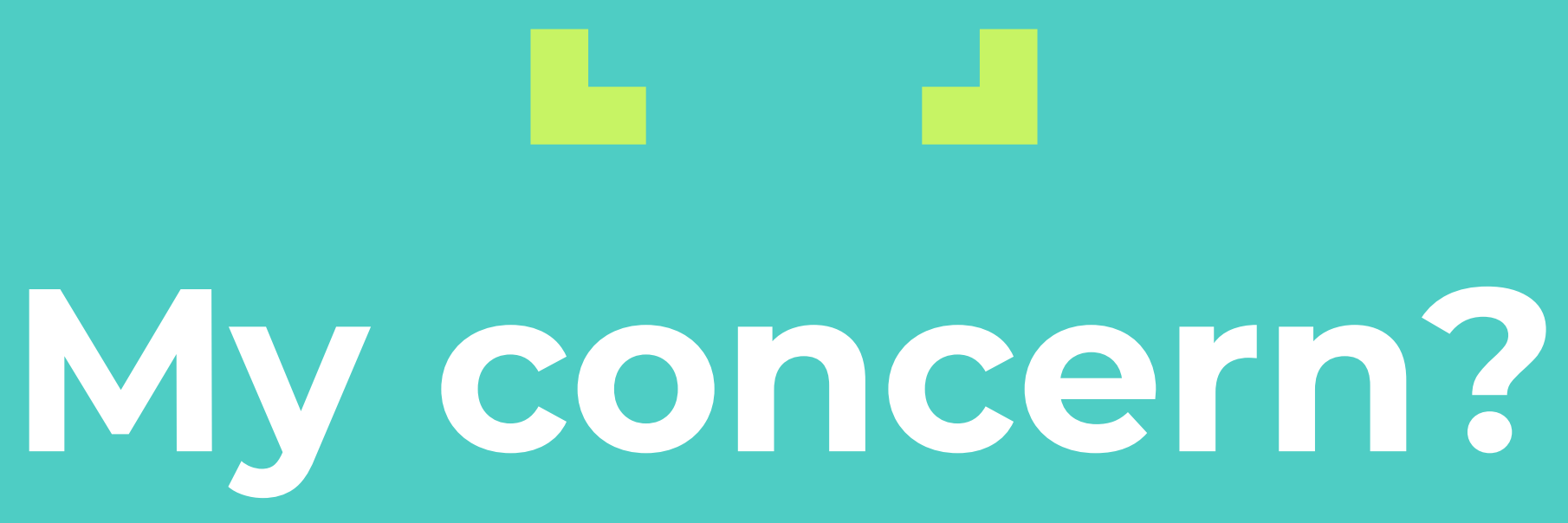

$1 / 2$ of the students at the University of Guelph had used alcohol before the age of 16 and more than $1 / 3$ had been drunk before the age of 16 (University of Guelph, 2014). 


\section{But why was I concerned?}

An early age of onset of alcohol use is a serious indicator of future alcohol use and abuse issues (Chou \& Pickering, 1992; Skidmore et al., 2011)

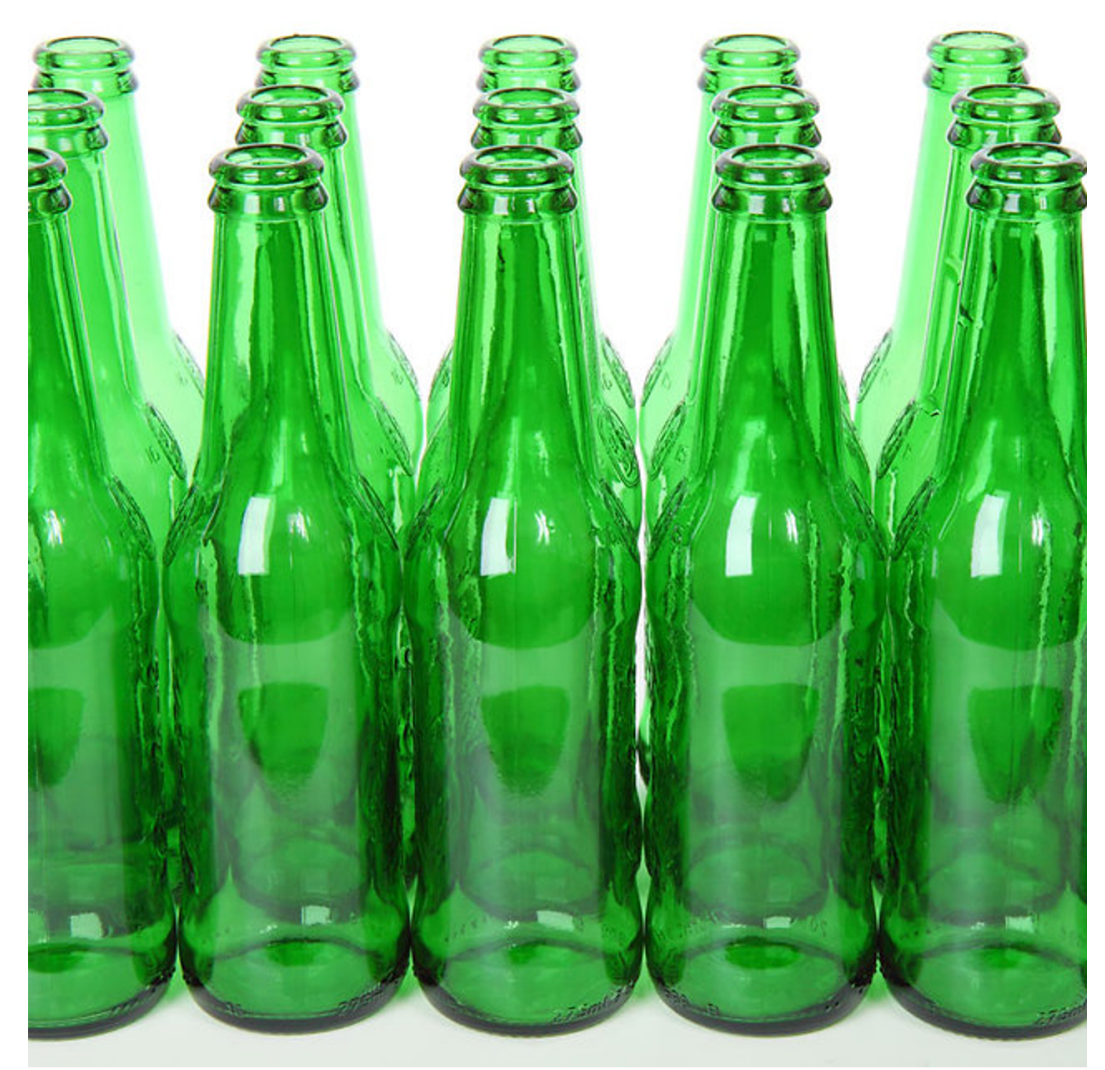




\section{1 \\ Did this have anything to do with the rural population?}

. 
What I've Learned
Literature and Data Available on Alcohol Use in Rural Youth 


\section{Alcohol Use amongst Ontario Youth is Dropping}

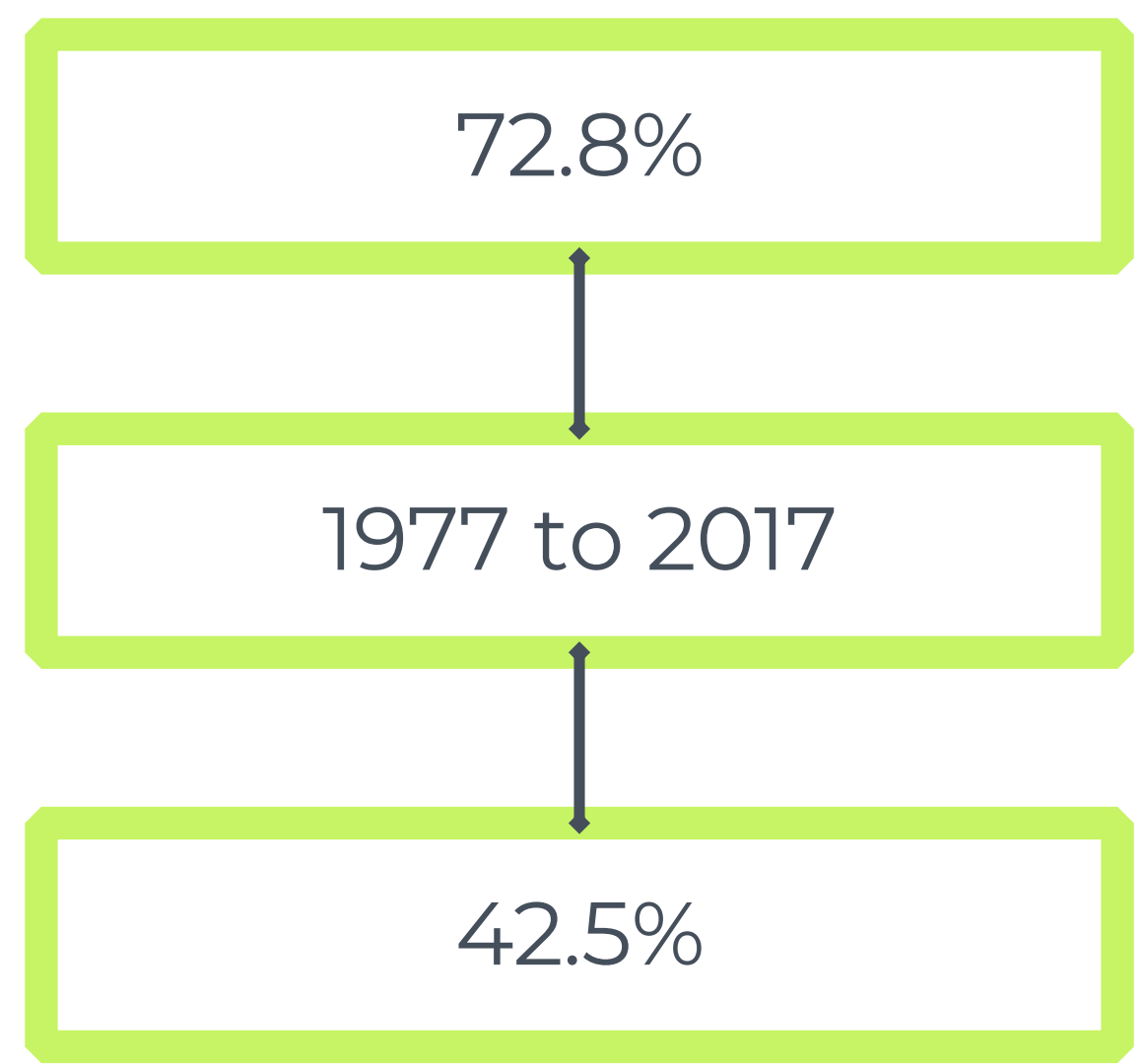




\section{Harmful \& hazardous}

drinking is at an all time low in the province

\section{Alcohol remains}

the most frequently used substance by youth

\section{Urban areas}

have lower rates of drunkenness amongst youth 


$$
\begin{aligned}
& \text { Reported } \\
& \text { rates of } \\
& \text { drunkenness } \\
& \text { by region }
\end{aligned}
$$




\section{$13.4 \%$}

Greater Toronto Area

\section{$17.2 \%$}

North

$19.8 \%$ West

$17.3 \%$

East 


\section{Erie St. Clair \& South West LHINs}

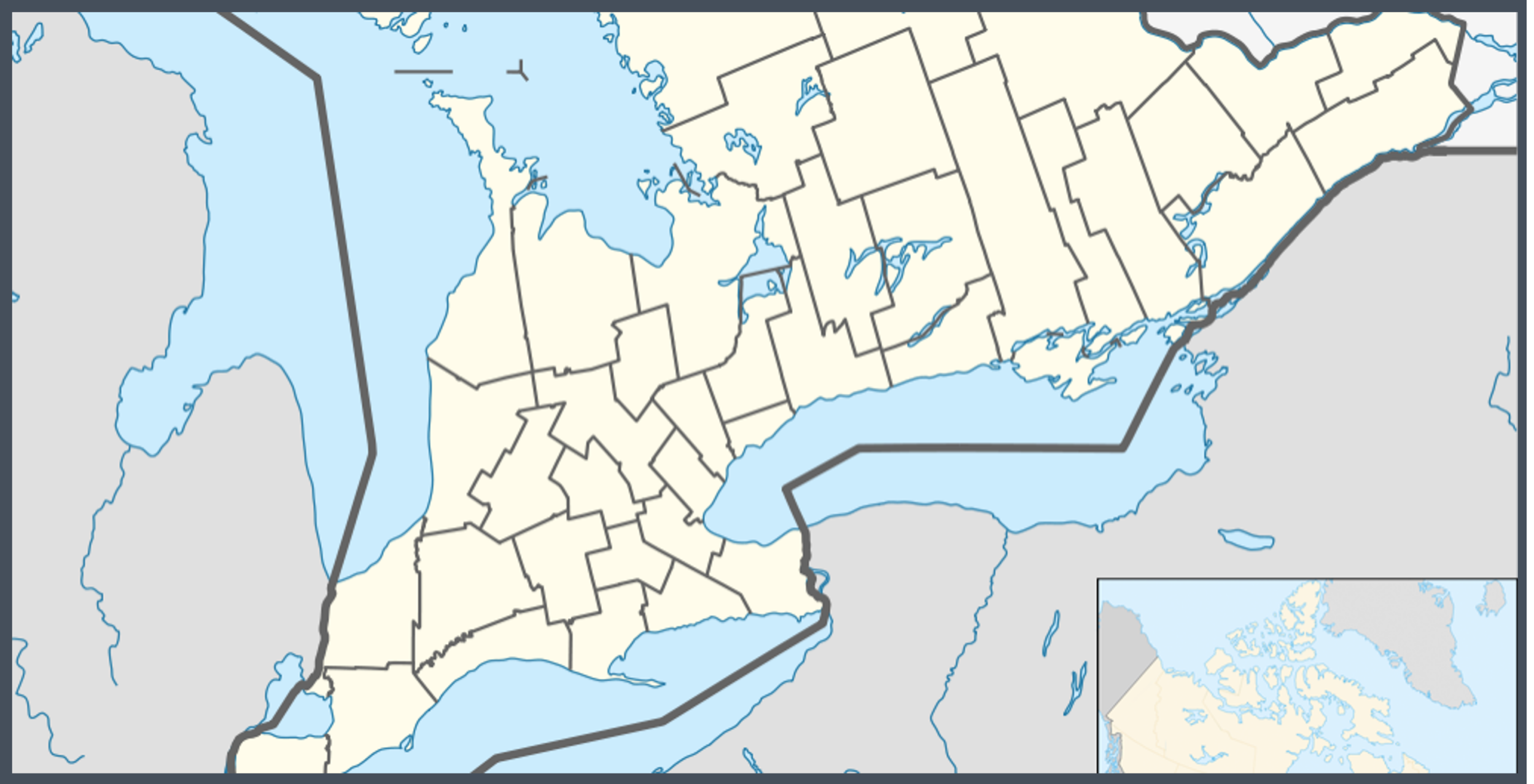




\section{Percentages of Students Reporting Alcohol Use in the Past Year}

\begin{tabular}{|c|c|c|c|}
\hline & Alcohol & Binge Drinking & Drunkenness \\
\hline $\begin{array}{r}\text { Erie St. Clair + } \\
\text { South West }\end{array}$ & 60.0 & 26.9 & 27.1 \\
\hline Central West & 41.1 & 11.1 & 8.9 \\
\hline $\begin{array}{r}\text { Toronto Central + } \\
\text { Central }\end{array}$ & 45.9 & 19.5 & 18.1 \\
\hline $\begin{array}{r}\text { North East }+ \text { North } \\
\text { West }\end{array}$ & 65.5 & 27.2 & 23.7 \\
\hline
\end{tabular}




\section{Rates of Hazardous and Harmful Drinking}

\begin{tabular}{rccc} 
& 1999 & 2007 & 2017 \\
\hline GTA & $\mathbf{1 7 . 0}$ & $\mathbf{2 0 . 4}$ & $\mathbf{1 2 . 2}$ \\
\hline North & $\mathbf{4 1 . 8}$ & $\mathbf{3 5 . 4}$ & $\mathbf{1 7 . 6}$ \\
\hline West & $\mathbf{2 9 . 8}$ & $\mathbf{2 9 . 5}$ & $\mathbf{2 0 . 1}$ \\
\hline East & $\mathbf{2 4 . 5}$ & $\mathbf{2 8 . 4}$ & $\mathbf{1 1 . 7}$
\end{tabular}




\section{What research is out there?}

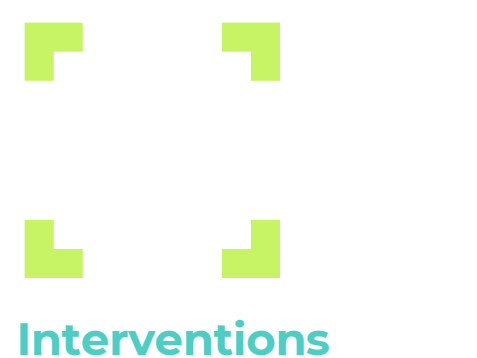

Often not studied or published by the community.

Social norming works.

International Data Cultural differences and merging.

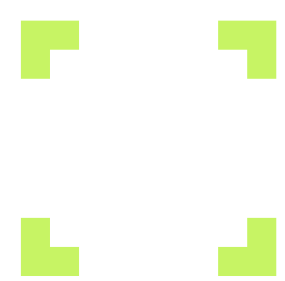

Impacts on Behaviours

Ethnicity, family, location etc.
Canadian Quantitative Data Provincial data.

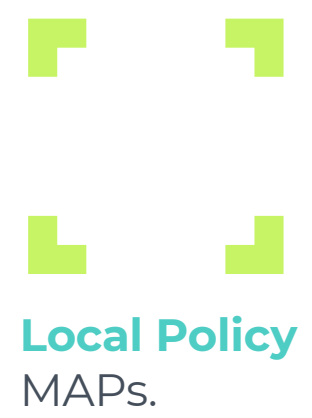

Educational initiatives.

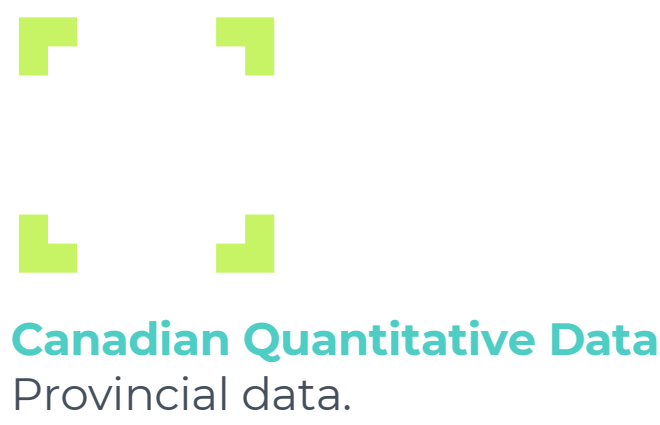




\section{Where to Next}

Research Plans 


\section{What's Missing?}




\section{What more do I want to learn?}

$\square$ To determine social and contextual factors that lead to the first instance of alcohol use

$\square$ To determine social and contextual factors that lead to subsequent alcohol use

$\square$ To investigate rural youths' reflections of their experiences of past instances of use and the impacts on their lives 


\section{In two or three columns}

Key Informant Interviews

Meeting with key adult community members.

e.g., health care providers, politicians, community organizations
Participatory Workshop

Discussing the harms associated with alcohol use amongst their peers.

Followed by invitation to interviews
Social Media Analysis

Review of party and drinking

events documented on social media by youth participants. 


\section{Canada's Low Risk Drinking Guidelines}

A Plug and Explanation 


\section{Canada's Low Risk Drinking Guidelines}

For Women

No more than

10 drinks a

week

No more than

2 drinks a day

on most days
For Men

No more than

15 drinks a

week

No more than

3 drinks a day

most days
For Special

\section{Occasions}

Reduce risk of injury and

harm by

drinking no

more than 3

drinks (for

women) or 4

drinks (for

men) on a

single

occasion 


\section{Just so we're clear..}

$341 \mathrm{ml}$ (12 oz.) glass of $5 \%$ alcohol content

e.g., beer, cider, cooler

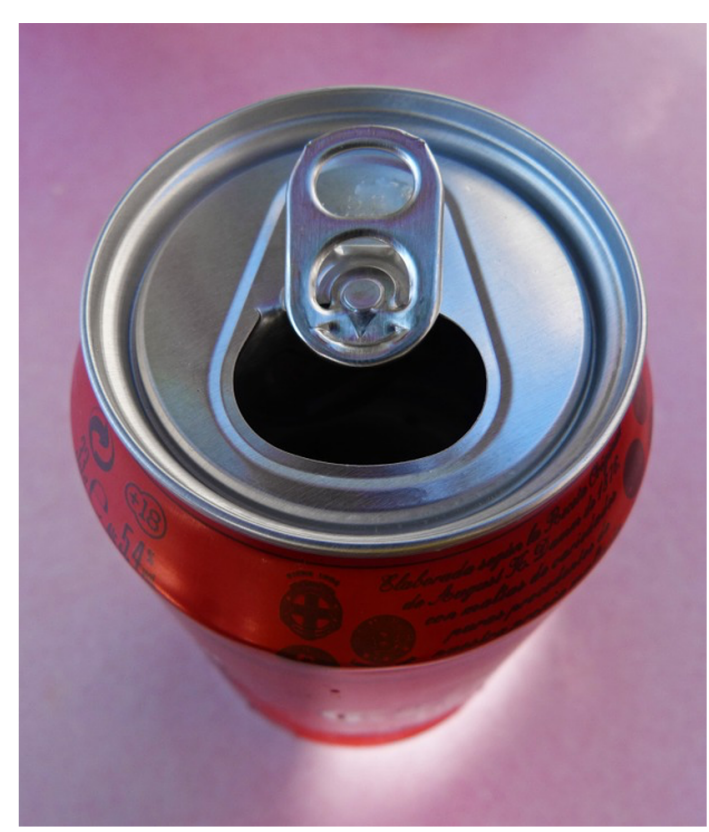

$142 \mathrm{ml}(5 \mathrm{oz}$ ) glass of $12 \%$ alcohol content

e.g., wine

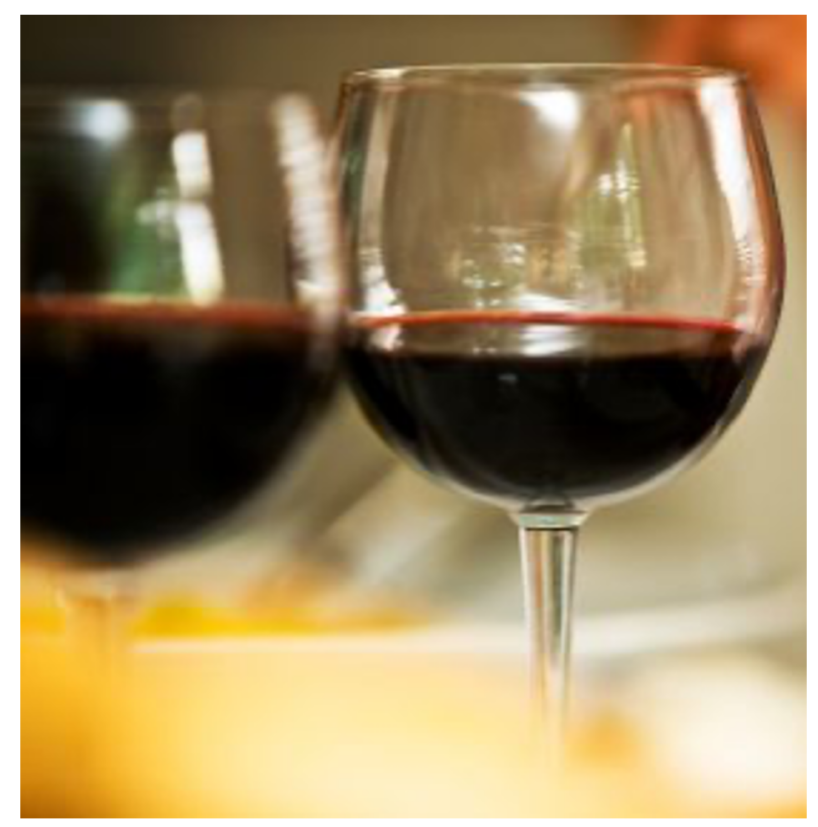

$43 \mathrm{ml}$ (1.5 oz.) serving of $40 \%$ alcohol content e.g., gin, rum, whiskey

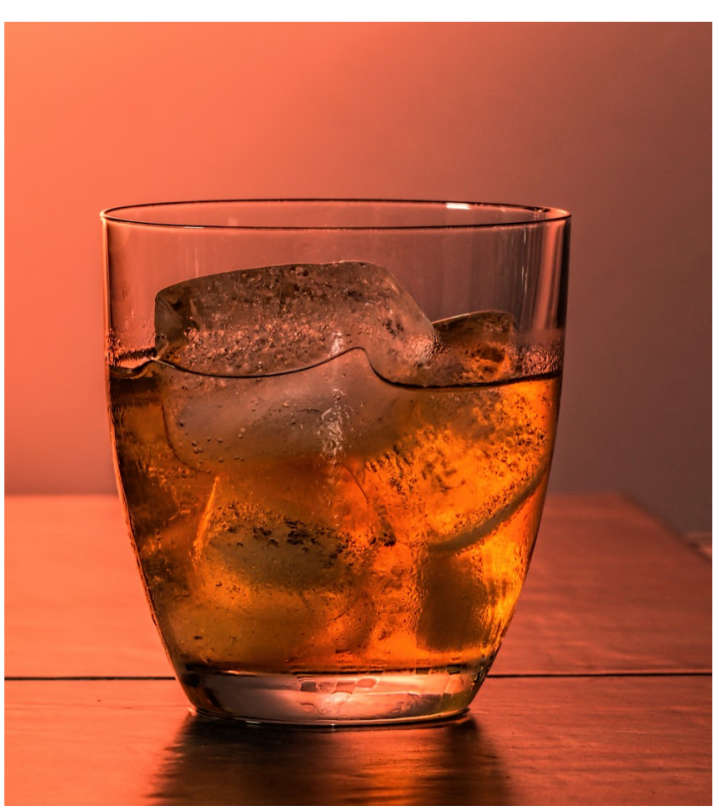




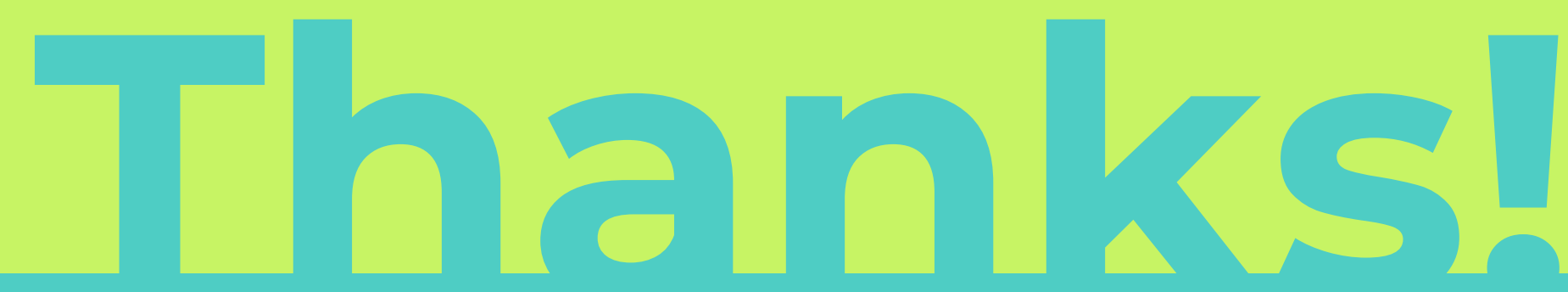

Any questions?

You can find me at

thompsja@uoguelph.ca 


\section{Credits}

Special thanks to all the people who made and released these awesome resources for free:

$\square$ Presentation template by SlidesCarnival

$\square$ Photographs by Unsplash 